\title{
Worth It or Not: Effects of Price Premium on Purchase Intent of Products with Environmental Benefits
}

\author{
Yali Fan \\ Tsinghua University \\ Rong Chen \\ Tsinghua University \\ Zhuoyi Fan \\ Tsinghua University
}

Since the green products' costs increase, how to persuade consumers to accept the premium price is central to the green marketing. This paper demonstrates that consumers infer higher perceived quality is not necessary to increase purchase intent, and perceived price fairness plays a vital role in consumers' purchase intent on green products. These results are explained by consumers' equity theory related to price fairness. The present study introduces a moderator of types of concern. The authors put forward some suggestions to increase consumer acceptance of green products at a premium price.

Keywords: Green Product, Environmental Sustainability, Perceived Price Fairness, Price Premium

\section{INTRODUCTION}

As the threat from environmental damages increases, how to improve consumers' environmental awareness and sustainable behavior becomes increasingly important (IPCC 2018). In turn, this growing concern and sense of social responsibility have spawned tremendous growth in the green (or sustainable, environmental, eco-friendly) market.

Broadly speaking, firms introduce green products performing in a way to comply with consumers' increasing awareness of environmental issues, improving or adding green features including parts made with materials that reduce the environmental impact from their products (Delmas and Burbano 2011), which is orthogonal to the products' performance. For example, BMW has reduced carbon dioxide emissions of newly sold vehicles in Europe (EU-28) by 40\% between 1995 and 2015(BMW 2015), The Procter \& Gamble Company released the new liquid laundry detergent, Tide purclean highlighted a full $65 \%$ of its ingredients come from plants and other renewables (P\&G 2016). Similarly, when Apple company release the designs for iPhone $6 \mathrm{~S}$, they highlighted that the carbon footprint of iPhone $6 \mathrm{~s}$ aluminum case is $50 \%$ of the previous generation by using scrap aluminum (Apple 2016).

Comparing to traditional products, these green products tend to be used safer chemicals and conserve energy, water, and materials, all these characteristics benefit directly to consumers less, but contribute to 
the whole community more, which shows primarily public features. In addition, since firms throw more efforts into new green products and spend more costs comparing with the previous one. Only being able to sell the new green one at a premium price would never allow firms to break even. One question that naturally arises is: when consumer face green products with premium, how would make a choice?

According to previous findings, a body of literature examined how consumers make a green decision, and researchers have discussed this topic from various angles (e.g. Brough et al. 2016; Cho \& Burton 2017; Haws, Winterich, \& Naylor 2014). Less is known how consumers respond to a product with environmental benefit attributes with a premium price.

Basically, firms introduce green products performing in two ways to comply with customers' increasing awareness of environmental issues, one is keeping the original price of green products since the producers are willing to bear the extra costs themselves as companies pursue goals to become more sustainable and pay attention to their products' carbon footprints, which leaves a more sustainable impression on consumers show great concerns in green materials, for example, Coca Cola applies PlantBottle ${ }^{\mathrm{TM}}$ to strengthen their green company image (Coca Cola 2016). Generally, it is estimated that companies like Coca-Cola pay $15-20 \%$ and even up to $25 \%$ more for green materials used in packaging (Carus \& Beckmann 2014). One question arises: will consumers choose these green products with original price?

Generally speaking, the price is a good indication of quality within a price range, low prices consistently refer to the lower quality, high prices consistently lead to higher quality (Langhe et al. 2014). Since green products cost more than their traditional counterparts, once they keep the original price, it seems the green products cut the price in that green products should rise the price but not in reality. Therefore, consumers may infer that sustainable products own lower quality according to the price-quality relationship (Wolinsky 1983).

Alternatively, firms rise in the price of green products, which maintains company profits and early technical expertise (Carus, Eder, \& Beckmann 2014). When consumers involve in the premium situation with functionality/environmental friendly attributes trade-offs, they will prefer to explore the value of money (Lee \& Min 2014). Furthermore, previous research shows that the environmental problem is usually related to personal short-term profit and social long-term detriments, whereas environmental protection behavior normally imposes personal costs instead of personal benefits (Montada \& Kals 1995) [16]. Conflicts arise, therefore, confront with personal short-term cost and social long-term effects, will consumer accept premium of green products?

The present studies focus on reasoning on the price premium of green products, and, specifically, how the communication of price premium affects consumers' purchase decisions. Since the green market is a typical information asymmetry market and green products own credence property, it is difficult for consumers to distinguish environmentally friendly products well even after consumption, which led to more false information on green products (Giannakas 2002). When product information is not sufficient, consumers may infer product performance through the price of products, and the price plays a signal role (Wolinsky 1983). However, less is known how consumers infer the premium of green products, as a signal of quality assurance or improving green attributes? If consumers assume the premium as a cue of quality assurance, they will be willingness to purchase the sustainable products as they assume that they contribute to the society by buying the green product without influencing the performance of green product (Koschate-Fischer, Stefan, \& Hoyer 2012; Griskevicius, Tybur, \& Van 2010; Liu, Chen \& He 2015). However, it is not necessary for consumers to deem the premium as a cue of quality assurance, they may presume the premium as a signal of green attributes. If this is the case, then consumers infer that the firm put more efforts into environment improvement of products and invests fewer efforts in quality from lay theories (Newman, Gorlin, \& Dhar 2014). As such, the decrease in quality leads to lower willingness to pay sustainable products.

We also focus on how the communication of environmental benefits influences consumers' willingness to pay green products with premium. A firm puts up the price of products with adding a new environmental attribute to the product without communication information, consumers may infer that the company pass on all costs of developing the new green attributes to them, feel perceived price unfairness 
strongly, and reject to pay the bill for the green attributes eventually. Supposing the firm justify the price premium of the green product, such as transmitting to consumers that the green product receives subsidies from other groups, such as government or the nonprofit organization in the research and development process, customers probably use counterfactual thinking: the firm will surcharge more if the group doesn't offer the subsidies, in other words, consumers merely pay less premium for the new green feature, they will perceive price fairness and tend to decrease consumers 'price sensitivity and increase the willingness to pay the green product at a premium.

The current research is conducive to two important stream of literature. First, previous research on green product evaluations have examined perceived quality of products and purchase intention, but less research has explored the response of consumers to the price premium and the mechanism of the consumers'response. Second, we build on work, especially, in the green product using equity theory showing that the presence of the green attribute drives consumers' perceived price fairness, in hence, influences the willingness to pay a premium. Furthermore, considering that producing sustainable products is receiving more and more attention, our results may contribute to practical implications for price-setting of green products on the marketplace.

\section{THEORETICAL BACKGROUND}

\section{Consumer Attitude to Green Products}

Previous researchers have conducted a large amount of research on green decision making from several perspectives. Some scholars have explored that consumers perceived the effectiveness of green products based on lay theory (Newman, Gorlin, \& Dhar 2014; Lin \& Chang 2013; Luchs et al. 2010). Some researchers have examined the purchase intentions from consumers features (Haws, Winterich, \& Naylor 2014; Goldstein, Cialdini, \& Griskevicius 2008; Ward \& Dahl 2014). Other researchers have found the effect of green attributes on the evaluation of the brand or products (Olsen, Slotegraaf, \& Chandukala 2014; Gershoff 2015). Last, some researchers had conducted how the behavior of purchasing green products influence morality (Mazar \& Zhong 2010).

Previous study is necessary and tries to evaluate the greenness of the products based on the overall evaluation or explicit elements of the consumer acceptance of green products. To date, less research has improved the consumer's green products preference from the perspective of consumer utility evaluation, especially investigated how consumer's response to the green products with premium price and explored the mechanism of this response. To fill this gap, we focus on exploring how adding a green feature or attribute of a product with price premium influences consumers' willingness to pay the premium.

\section{Product Externality, Signal Effect, and Resource Balance}

Environmental friendly products are always charged higher than their regular counterparts (HKTDC 2011). Studies have found that consumers would rather pay a premium for self-benefit product categories than other-benefit product categories (Carus, Eder, \& Beckmann 2014; HKTDC 2011; Soler, Gil, \& Sanchez 2002) since green products, especially product with other-benefit possesses the externality, which is benefit more for the community than consumer themselves, benefit for community directly and for consumers indirectly (Montada \& Kals 1995).

We propose that consumers may infer a product's premium as a signal of green improving or a signal of quality assurance from the signal theory (Boulding \& Kirmani 1993; Bagwell \& Riordan 1991). As a green product, consumers infer that firms surcharge due to green improving, in other words, consumers deem the price premium as a signal of green improving. Consumers infer the materials are hard to acquire or the manufacturing technology costs more. Alternatively, the price is also a signal of quality as a mechanism to solve problems that arise from asymmetric information between consumers and firms (Kirmani \& Rao 2000), it means consumers may infer the price premium as a signal of quality assurance. More and more research mentions that firms could improve environmental performance and also reduce costs of products. Since consumer infer the quality of green products is less effective than regular product 
from lay theory (e.g., Newman, Gorlin, \& Dhar 2014; Lin \& Chang 2013), and the price premium may signal the quality assurance.

\section{Reasoning about Perceived Price Fairness}

An important indicator of purchase intentions for green products is perceived price fairness (Wertenbroch \& Skiera 2002; Essoussi \& Linton 2010), a consumer's perceived price of a product or a service as right, just, or legitimate based on perceived input (such as price, information collection) and output (such as product quality) (Campbell 1999), consumers assess the price as fair if their perceived output from the product is more than their perceived input (e.g., Xia, Monroe, \& Cox 2004).

Basically, consumers judge the quality of the product usually by two ways, at first, consumers try to obtain information as much as possible. When consumers could not obtain sufficient product quality information, consumers will adopt the price to speculate the product quality, specially, the price represents quality level the product, which means price usually plays a signal role (Wolinsky 1983). A body of consumer research suggests that price is a positive indication of quality, consumers assume that different quality corresponds to different price, and higher price means higher quality, that is, "You get what you pay for" (Caves \& Greene 1996), in this case, consumers perceive the product price is fair (Dawar \& Sarvary 1997).

If consumers understand the value of green products as a contribution to the environment, they feel that they are doing something for the community (e.g., Koschate-Fischer, Stefan, \& Hoyer 2012), consumers will balance their values (product quality and added value) with cost, assess the price of the product, but if consumers infer that if firms do not put the cost into improving the environment, the cost of the product will be lower, consumers perceive the higher cost sacrifice and perceive price unfair (Habel et al 2016).

In summary, combining the literatures on signal effect and perceived price fairness, we infer that consumers should show less willingness to purchase green products with price premium than counterparts with original price. We also explore the mechanism to promote green products from perceived price fairness, specially, consumers will be more likely to purchase the product with green enhancement and price premium when they perceive the price fairness in the way others also make contributions to green products. In a formal statement, we make the following three hypotheses:

H1: Consumers will speculate that the quality of products with green enhancements and the original price is lower than the products with green enhancements and price premium from signal theory.

H2: Consumers will show more willingness to pay for the green product with original price than its counterpart with a premium.

H3: Consumer will more likely to purchase the product with green enhancements and price premium by presented the price premium as a signal of quality assurance clearly (vs. no information about price premium).

\section{OVERVIEW OF STUDIES}

To test these hypotheses, we will conduct two studies. Study 1 lend supports for the two hypotheses with regard to quality inference (H1) and purchase intention (H2). Additionally, this study also excluded one alternative mechanism for the effect, which is referred to the possibility that the price premium signals the green enhancements (We discuss this alternative in further detail along with the study.)

Study 2 tries to explore the mechanism to increase the willingness to pay the product with green enhancements and price premium. This study finds consumers 'perceived price fairness is key indicator to influence to pay the green products. 


\section{Study 1 \\ Introduction}

The first study tested the hypothesis that consumers infer the quality of products with green enhancements and the original price is lower versus price premium from signal theory. Additionally, we also tested the hypothesis consumers show higher willingness to pay for a green product with original price versus price premium.

Study 1 also examined one potential alternative explanation for the signal as a quality. The explanation is that consumers may infer the price premium of products with green enhancements as improving environment not quality assurance since firms throw more efforts into new green products and spend more costs comparing with the previous one. To test this alternative, study 1 also includes qualitysignal condition in which participants were explicitly informed that price is often an indicator of quality, and green-signal condition in which participants were explicitly notified that green enhancement is often accompanied with a price premium. Our proposed price premium signaling quality assurance, predicts that perceived quality of product with green enhancement in only-premium condition should have no difference with perceived quality in quality-signal condition, but have different perceived quality with the green-signal condition.

\section{Method}

Seventy adult participants were recruited from a north China university (Mage $=21,25.7 \%$ female), were randomized to one of four conditions (original-price, price-premium, green-signal, and qualitysignal) and read the description of a smart table lamp imbuing with green attributes. In all cases, the products were described as "significantly beneficial to environment". In three situations of pricepremium, green-signal, and quality-signal, participants were presented by "the price of the new smart table lamp rose by $10 \%$ compared with the original one", in original-price situation, participants were told "the price of the new smart table lamp keeps the same". Different from original-price and price-premium situations, participants in quality-signal and green-signal condition read a short description before the product information, specifically, in quality-signal condition, participants were explicitly told that price is closely related to quality, and in green-signal condition, participants were explicitly presented that green enhancement is accompanied with price premium (see App. A), after these two priming description, subjects were asked to fill 3 questions related to the description and make a conclusion of the description.

After reading description, all participants answered several questions which assessed purchase intent, perceived quality, and perceived greenness. Specifically, participants responded to 3 items assessing purchase intent (e.g. Compared to the old table lamp, what's a possibility you buy this new smart lamp? Compared to the old table lamp, what's purchase intention you buy this new smart lamp? What's a possibility you recommend family and friends to buy this new smart table lamp? $1=100 \%$ purchase old smart lamp, $5=$ average, $9=100 \%$ purchase new smart lamp). Participants also evaluated perceived product quality through their agreement with the three statements "The quality of the new smart table lamp is very good", "The new smart lamp provides a good lighting", and "The quality of this new smart lamp is very reliable" (1= not at all, 9= very much so). Finally, participants also evaluated perceived greenness of smart lamp through their agreement with the following statements on a nine-point scale: "This new smart lamp is worth to be certificated green label", "Purchasing this new smart lamp is a good choice for the environment", and "A person who is concerned about environment show higher willingness to pay for this new smart lamp." Participants also indicate "How green is this new smart lamp?" (1= not at all, 9= "extremely" environmentally friendly).

\section{Results}

Purchase Intent. Study 1's results are showed in figure 1. The three items regard to purchase intent for the products were highly correlated $(r=0.74)$ and were averaged to produce one measure of purchase intent. A one-way ANOVA revealed a significant effect of the price premium of purchase intent for the new smart lamp, $F(3,66)=3.09, p=.033$. In agreement with our predictions, a planned contrast showed that participants manifested higher purchase intent in the three following scenarios (original-price 
situation, green-signal and quality-signal $)$ than price-premium situation $\left(M_{\text {original }}=7.31, \mathrm{SD}=1.09\right.$ versus $M_{\text {premium }}=6.44, \mathrm{SD}=1.54, M_{\text {quality }}=7.63, \mathrm{SD}=0.698$ versus $\left.M_{\text {green }}=7.15, \mathrm{SD}=1.27\right)$, respectively, $p=$ $.034,0.079$ and 0.005 , and not significantly different from quality-signal situation and green-signal situation, $\mathrm{p}>.1$.

\section{FIGURE 1 \\ MEAN RATINGS OF PURCHASE INTENT, PERCEIVED PRODUCT QUALITY, AND PERCEIVED GREENNESS (STUDY 1)}

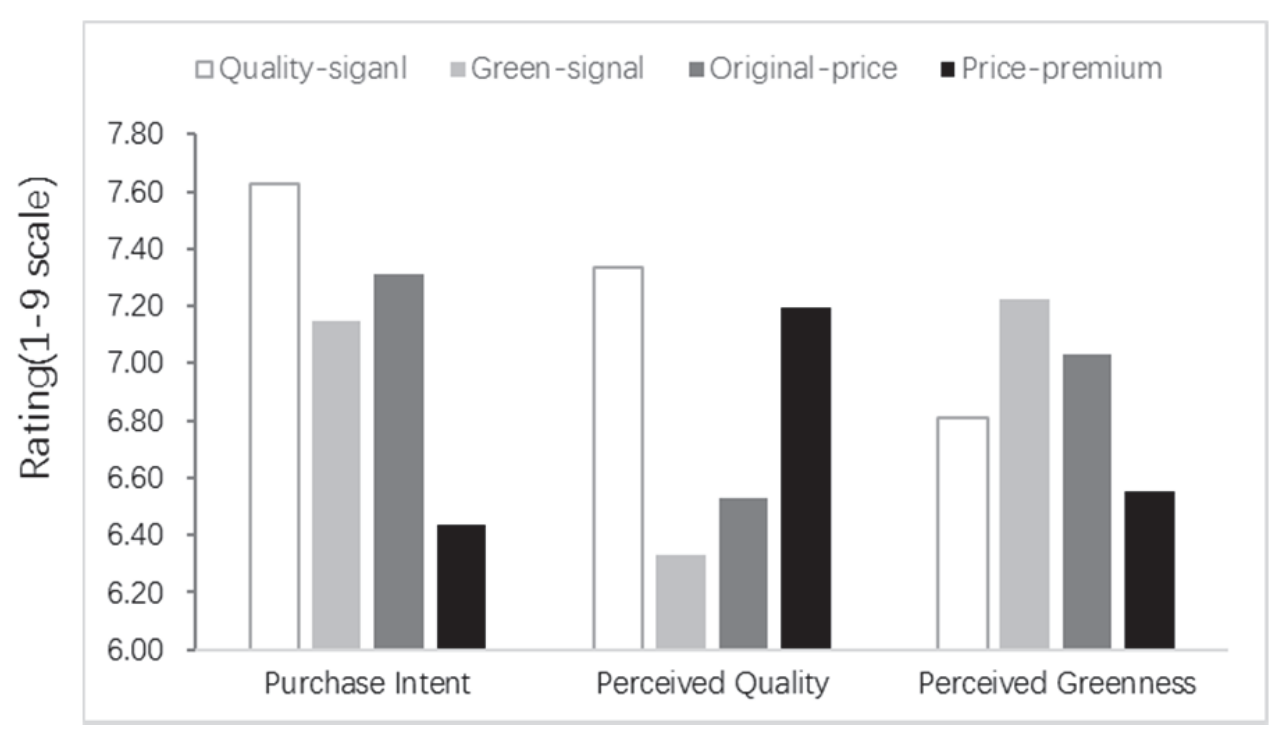

Perceived Product Quality. The three items related to perceived product quality were highly correlated for the products $(r=0.93)$ and were averaged to create one measure of perceived product quality. A one-way ANOVA showed a significant effect of the price premium of purchase intent for the new smart lamp, $F(3,66)=3.06, p=.036$. In agreement with our hypothesis, a planned contrast revealed that participants performed significantly higher perceived quality in quality-signal condition than the green-signal and original-price condition (Mquality $=7.33, S D=1.33$ versus Moriginal $=6.53, S D=1.07$, $M$ green $=6.33, S D=1.05)$, respectively, $p=.016,0.054$, and participants also expressed significantly higher perceived quality in price-premium condition than the green-signal and original-price condition $(M$ premium $=7.19, S D=1.24$ versus $M$ original $=6.53, S D=1.07, M$ green $=6.33, S D=1.05)$, respectively, $\mathrm{p}=.030,0.096$, and not significantly different from quality-signal situation and pricepremium situation, $p>.1$.

Perceive Product Greenness. The four items regarding to perceived product greenness were highly correlated $(r=0.84)$ and were averaged to generate one measure of perceived product greenness. A oneway ANOVA revealed no significant effect of the price premium of perceived greenness for the new smart lamp.

\section{Conclusion}

Results stemmed from study 1 accordance relationship with hypotheses summarized in the introduction. Specifically, consumers would like to purchase green products keeping original price than its counterparts with a premium, but they perceive lower quality of products with green enhancements in the original-price situation than price-premium. Moreover, this study also established that consumers perceive the price premium of products as a signal of quality assurance rather than green enhancements, and quality-signal could improve the purchase intention of green products. According to these points, it 
may predicate that quality is not a good indicator for purchase intention of green products. We try to find the possible mechanism of purchasing products with green enhancements in study 2 .

\section{Study 2 \\ Introduction}

Study 1 found support for the hypothesis that consumers infer the premium of green products as a quality signal and also show less willingness to pay for green product with price premium than original price even though they perceive higher quality of green products with price premium than original price, this situation reverses if consumers are informed explicitly quality often accompanied with price premium, specially, when consumers was emphasized firm throw more efforts and costs to improve quality, consumer would more likely to purchase the green products with premium. Study 2 lent supports for the moderation (hypothesis 3) and tried to explore the mechanism of this behavior and also find a boundary condition of self-concern and other-concern.

Pricing literature has deemed that perceived quality is an important index in price evaluation (Zeithaml 1988, Sweeney \& Soutar 2001). In other words, consumers form a price assessment through engaging in mental trade-offs between perceived cost losses and perceived quality gains. One of the important indicators is customers' perceived price fairness. Habel (2016) explores that the motivation of Corporate Social Responsibility (CSR) practices will influence the consumer's perceived price fairness. Fewer researchers have explored the mechanism of consumers' response to the price premium of green products. We hypothesize that one important factor influence consumers to purchase green products is perceived price fairness.

Study 2 tested this hypothesis straightly. We forecasted that when consumers realize the products with green enhancements are sponsored by a third party, such as government subsidies, they will infer that there are more people contributing to environmental protection rather than themselves. Therefore, we predicted higher perceived price fairness leads to a higher willingness to pay. To explore what consumers surmise without information, this study included a control condition in which no social cue information was provided.

Montada and Kals (1995) deem that engaging in protecting environment generally incur the costs but does not come with personal benefits, this research also focuses on self-concern and other-concern. In this way, the present study explores significant and previously undone research questions related to the moderating role of self-concern and other-concern on government subsidies versus control situation. These findings have important significance in theory and practice in green marketing.

\section{Method}

Seventy-five adult participants were recruited from a north China university (Mage $=21,37.3 \%$ female) and were randomized to one of four conditions in a 2 concern (self-concern vs. other-concern) $\mathrm{X}$ 2 cues (control vs. government subsidies) design. we use a priming technique (Chen, Xu, \& Shen 2016) to manipulate self-concern and other-concern. At the beginning, participants fulfil a priming task and they are required to unscramble ten four-word sentences to create a three-word sentence by dropping an unrelated word. Unrelated words were either regarding to self-concern or other-concern (see App. B), depending on the condition. After finishing the priming test, all participants are asked to read a short depiction regarding a green product (a laundry detergent). In this case, the laundry detergent was described as "significantly beneficial to environment". In the government subsidies condition, participants were showed the description as "government offer this new product a certain degree of government subsidies." While in the control condition, there was no information about subsidies.

After reading the product information, all respondents then evaluated their purchase intent, perceived quality, and perceived greenness by answering several questions. In particular, participants replied to 3 items related to purchase intent (e.g. Compared to the old laundry detergent, what's a possibility you buy this new laundry detergent? Compared to the old laundry detergent, what's purchase intention when you buy this new laundry detergent? What's a possibility you recommend family and friends to buy this new laundry detergent? $1=100 \%$ purchase old laundry detergent, $5=$ average, $9=100 \%$ purchase new laundry 
detergent). All participants then evaluated the price fairness of the new laundry detergent through their agreement with the three statements "This new laundry detergent offers a fair price", "This new laundry detergent offer a reasonable price", and "This new laundry detergent offer a just price" $(1=$ not at all, $5=$ average, $9=$ very much so).

\section{Results}

Purchase Intent: Research findings from this study are showed in figure 2. A two-way ANOVA showed a significant interactive effect between the manipulation (self-concern vs. other-concern) and cue (no cue vs. government subsidies), $F(1,71)=4.04, p=.048$. Consistent with our hypothesis, purchase intent was higher when presenting government subsidies compared to control group $\left(M_{\mathrm{gov}}=6.74, \mathrm{SD}=\right.$ 1.06 vs. $\left.\left.M_{\text {control }}=5.94, \mathrm{SD}=1.36\right), t(1,33)=-2.863, p=.005\right)$. However, when the self-concern and other-concern were showed to participants, there was a moderation effect, specifically, when presenting other-concern (vs. self-concern), consumers in government subsidies situation showed less purchase intent relative to control group $\left(M_{\mathrm{gov}+\text { other }}=6.75, \mathrm{SD}=.25\right.$ vs. $M_{\text {control+other }}=6.52, \mathrm{SD}=0.29, M_{\mathrm{gov}+\text { self }}=$ $6.73, \mathrm{SD}=.26$ vs. $\left.M_{\text {control+self }}=5.43, \mathrm{SD}=.27\right)$.

\section{FIGURE 2 \\ PURCHASE INTENT'S RATING IN STUDY 2}

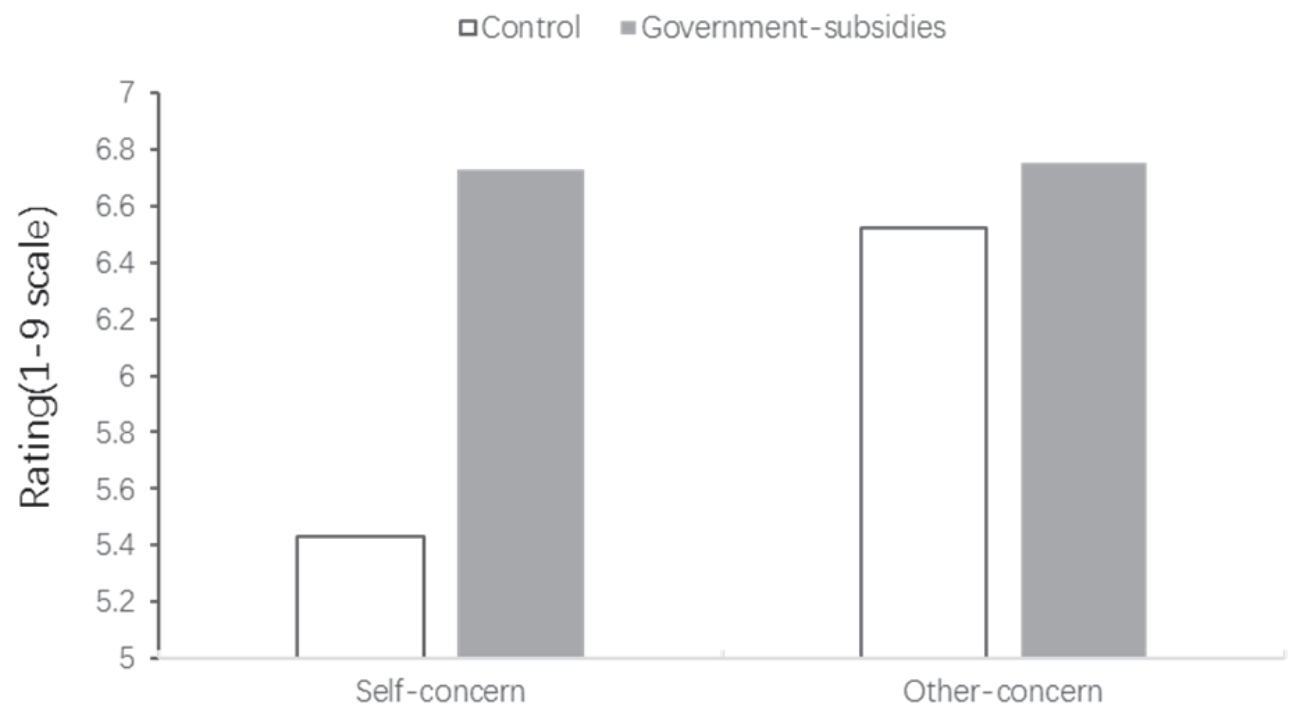

Perceived Price Fairness: The three items regarding price fairness were highly correlated $(r=0.84)$. A two-way ANOVA showed a marginal interactive effect between the manipulation (self-concern vs. other-concern) and cue (no cue vs. government subsidies), $F(1,71)=2.22, p=.09$. Consistent with our hypothesis, perceived price fairness was higher when presenting government subsidies compared to control group $\left(M_{\mathrm{gov}}=7.18, \mathrm{SD}=1.06\right.$ vs. $\left.\left.M_{\text {control }}=6.68, \mathrm{SD}=1.19\right), t(1,33)=-2.86, p=.005\right)$. However, when the self-concern and other-concern were showed to participants, there was a moderation effect, specifically, when presenting other-concern (vs. self-concern), consumers in government subsidies situation showed less perceived price fairness relative to control group $\left(M_{\mathrm{gov}+\text { other }}=6.97, \mathrm{SD}=.24\right.$ vs. $M_{\text {control+other }}=6.92, \mathrm{SD}=0.28, M_{\text {gov }+ \text { self }}=7.40, \mathrm{SD}=.25 \mathrm{vs} . M_{\text {control }+ \text { self }}=6.46, \mathrm{SD}=.26$ ).

Mediation: We applied a moderated mediation analysis to examine the predicated relationship of cues by kind of concern on purchase intent by means of the mediator of perceived price fairness. We entered these variables into analysis by the bootstrap analysis with 5,000 samples [40] (Preacher \& Hayes 2008): cues as the predictor variable, concerns (self-concern vs. other-concern) as the moderator, and perceived price fairness was the mediators. Results showed that the moderated mediation model was significant, 
$R^{2}=0.482, \mathrm{p}<.0001$, As predicated, perceived price fairness mediated the effect of cues on purchase intent for the green product (self-concern) since the indirect effect is significant $(\beta=.222,95 \% \mathrm{CI}=.009$ to .606), indicating that the predicted moderated mediation model interpreted our data.

\section{Discussion}

In sum, purchase intent and perceived price fairness showed the predicted model of results: when presenting social cues like governments subsidies (vs. no information), consumers rated more favorably (higher perceived price fairness and higher purchase intent) to purchase a product with green enhancements. We further specified by the results of the mediation analysis. We observed that the effect of social cues on purchase intent was mediated by perceived price fairness.

This study also identified a moderation effect of self-concern and other-concern. When consumers were presented self-concern information, consumers would perform same pattern on purchasing products with green enhancements, however, when consumers were presented otherconcern information, consumers would perform differently on purchasing products with green enhancements. It further suggests that if firms are able to stimulate consumers' other-concern, they may be able to promote sales of green products.

We are able to stimulate consumers' other-concern, they may be able to promote sales of green products.

\section{GENERAL DISCUSSION}

Pricing has been central to marketing. However, to date, less is known about how consumers' response to price premium of green products with green enhancements and also examine why these differences exist in sustainable behavior. These present studies try to fix this gap, shed lights on presenting information about "every extra penny deserves its value" and supports from other social organization such as government will increase the willingness to pay product with green enhancements.

These studies also explore this mechanism while eliminating an alternative explanation. Study 1 found that differences in perceived quality between price premium and original price, as it is known to all, consumer showed higher purchase intent to green products with original price (vs. price premium), however, study 1 also established consumer infer the quality of green products with original price is lower (vs. price premium).

Study 1 also offers more supports for the proposed path by addressing a potential alternative explanation. In particular, study 1 unfolded that presenting two situations: quality-signal situation in which it is explicitly stated that price is a guarantee for quality and green signal situation in which it is showed that companies throw huge amounts of costs in developing a new green product. We observed that participants showed the same pattern in perceived quality of green products with price premium with the quality-signal situation, but different perceive quality with the green-signal situation. Moreover, this study indicated that these four group (original-price, price-premium, quality-signal, and green-signal) showed no difference on perceived greenness of products with green enhancements.

Study 2 identified the underlying reasons for this effect. In this study, we discovered that a key moderator of cues on purchase intent is whether the concern is self or other. A moderated mediation analysis showed that when consumer concern themselves more, social cues like government subsidies (vs. control) increase purchase intent to green products with price premium because of perceived price fairness. However, when consumer concern others more, social cues like government subsidies show no significant difference with the control group.

There exist several directions in which our research might be enriched through further research. First, we explore the mechanism of how consumer respond to price premium of products with green enhancement, however, even though some products have improved greenness, they still could keep the original price. This generates many interesting research directions on how consumers respond to this situation. For example, how to enhance their perceived quality? How do they perceive price fairness? Is it a good strategy to keep the original price when improving the greenness of products? 
Second, the authors use two categories product which is suitable for college students, to explore how consumers respond to price premium, in future research, it could explore more products to test robust of the mechanism. Except these, the project is intended to using green consumer products from enterprises to support field research activities based on experiments, research and interviews.

Third, this research only considers social cues, other-concern, self-concern, perceived price fairness, it could broaden this conception, such as green consumption value, social norms, trust and so on.

These findings have a lot of theoretical and practical meanings. One theoretical contribution of this research is that it explores consumer's response to green products with a price premium. Some researchers have explored the perceived effectiveness of green products (Newman, Gorlin, \& Dhar 2014; Lin \& Chang 2013; Luchs et al. 2010), but do not consider the price premium of products with green products. This research is one of the first to explore the consumers' response on the green product on a premium.

A second significant theoretical contribution of this research is that it involves concerns (self-concern and other-concern) as a vital moderator of consumer's perceived price fairness. While previous research has focused on values or attitudes, situation pressure, trust and so on (Lin \& Chang 2013; Haws, Winterich, \& Naylor 2014), less research has been conducted on taking into factors which probably increase the willingness to pay the green products with a price premium. In this background, our research indicates that consumers are more likely to accept the price premium with social cues like government subsidies through the perceived price fairness.

A third significant theoretical contribution of this research is that it discovers conditions under which green products in a premium will increase consumer purchase intent. The green products often bring consumers' cost sacrifice and others' benefit, it is assumed that consumers with other-concern would like to buy the green product no matter whether the social cue presents.

From a practical perspective, these results provide some new insights for a number of firms that offer green products at a premium. Consumers usually pay the green products at an approximately $20 \%-25 \%$ price premium in comparison with regular one (Lin \& Chang 2013), clearly, not all consumers would like to purchase green products (Haws, Winterich, \& Naylor 2014). Hence, these results may be especially important, as they propose perceived support from other organization like government increases purchase intent from consumers, eventually, to motivate firms to produce green products continually.

The results of study 1 and 2 suggest a second practical implication. Perceived quality is significantly important, however, compared with traditional products, improving consumers' perceived price fairness is also very necessary. Moreover, the results also indicate that other-concern is a mediator, it suggests that firms need to emphasize the other-concern when communicating with consumers, such as care for others.

This research provides one of the first research into the influence of price premium on consumer perception. These results are constructive because they indicate that (1) consumer infer the price premium as a signal of quality assurance not green enhancements, (2) even though consumers infer higher quality of green product with premium, they don't show high purchase intent; (3) presenting social cues like government subsidies could increase purchase intent; (4) perceived price fairness is a key mediator on purchase intern by social cues; (5)other-concern is important moderator on purchase intent by social cues, these results are also instructive since they not only shed light on how consumers respond to price premium of green products but also offer some insights to the firms paying more attention in producing green products.

\section{ACKNOWLEDGEMENTS}

The research for this project was supported by the National Natural Science Foundation of China (Grant No. 71772104, 71472104). 


\section{REFERENCES}

Apple. (2016). Environmental Responsibility Report, 2016 Progress Report, Covering Fiscal Year 2015. Retrieved from

http://images.apple.com/environment/pdf/Apple_Environmental_Responsibility_Report_2016.pdf

Bagwell, K., \& Riordan, M. H. (1991). High and declining prices signal product quality. The American Economic Review, 224-239. doi:10.2307/2006797

BMW. (2015). Sustainable Value Report 2015. Retrieved from https://www.bmwgroup.com/content/dam/bmw-groupwebsites/bmwgroup_com/responsibility/downloads/en/2015/BMW_SVR_2015_RZ_EN.pdf

Boulding, W., \& Kirmani, A. (1993). A consumer-side experimental examination of signaling theory: do consumers perceive warranties as signals of quality? Journal of consumer research, 20(1), 111123. doi: $10.2307 / 2489204$

Brough, A. R., Wilkie, J. E., Ma, J., Isaac, M. S., \& Gal, D. (2016). Is eco-friendly unmanly? The greenfeminine stereotype and its effect on sustainable consumption. Journal of Consumer Research, 43(4), 567-582. doi:10.1093/jcr/ucw044

Campbell, M. C. (1999). Perceptions of price unfairness: antecedents and consequences. Journal of marketing research, 187-199. doi:10.2307/3152092

Carus, M., Eder, A., \& Beckmann, J. (2014). Green Premium prices along the value chain of biobased products. Industrial Biotechnology, 10(2), 83-88. doi:10.1089/ind.2014.1512

Cho, Y. N., Soster, R. L., \& Burton, S. (2018). Enhancing environmentally conscious consumption through standardized sustainability information. Journal of Consumer Affairs, 52(2), 393-414. doi:10.1111/joca. 12172

Coca Cola. (2016). 2015 Sustainability Report. Retrieved from http://www.cocacolacompany.com/stories/2015-2016-sustainability-update-downloads\#5

Dawar, N., \& Sarvary, M. (1997). The signaling impact of low introductory price on perceived quality and trial. Marketing Letters, 8(3), 251-259. doi:10.2307/40216451

Delmas, M. A., \& Burbano, V. C. (2011). The drivers of greenwashing. California Management Review, 54(1), 64-87. doi:10.1525/cmr.2011.54.1.64

Essoussi, L. H., \& Linton, J. D. (2010). New or recycled products: how much are consumers willing to pay? Journal of Consumer Marketing, 27(5), 458-468. doi:10.1108/07363761011063358

Gershoff, A. D. (2015). What makes it green? the role of centrality of green attributes in evaluations of the greenness of products. Journal of Marketing, 79(1), 97-110. doi:10.1509/jm.13.0303

Giannakas, K. (2002). Information asymmetries and consumption decisions in organic food product markets. Canadian Journal of Agricultural Economics, 50(1), 35-50. doi:10.1111/j.1744-7976. 2002.tb00380.x

Goldstein, N. J., Cialdini, R. B., \& Griskevicius, V. (2008). A room with a viewpoint: using social norms to motivate environmental conservation in hotels. Journal of Consumer Research, 35(3), 472482. doi:10.1086/586910

Griskevicius, V., Tybur, J. M., \& Van, d. B. B. (2010). Going green to be seen: status, reputation, and conspicuous conservation. Journal of Personality \& Social Psychology, 98(3), 392-404. doi: $10.1037 / \mathrm{a} 0017346$

Habel, J., Schons, L. M., Alavi, S., \& Wieseke, J. (2016). Warm glow or extra charge? The ambivalent effect of corporate social responsibility activities on customers' perceived price fairness. Journal of Marketing, 80(1), 84-105. doi:10.1509/jm.14.0389

Haws, K. L., Winterich, K. P., \& Naylor, R. W. (2013). Seeing the world through green-tinted glasses: green consumption values and responses to environmentally friendly products. Journal of Consumer Psychology, 24(3), 336-354. doi: 10.1016/j.jcps.2013.11.002

HKTDC (2011). Shopping for green products on the Mainland (Executive Summary). Retrieved from http://economists-pick-research.hktdc.com/business-news/article/Research-Articles/Shoppingfor-green-products-on-the-Mainland-Executive-Summary-/rp/en/1/1X000000/1X09TR3O.htm 
Intergovernmental Panel on Climate Change (IPCC). Special Report: Global Warming of 1.5 。C. (2018). Retrieved from https://www.ipcc.ch/sr15/

Kirmani, A., \& Rao, A. R. (2000). No pain, no gain: a critical review of the literature on signaling unobservable product quality. Journal of Marketing, 64(2), 66-79. doi:10.1509/jmkg.64.2.66.18000

Koschate-Fischer, N., Stefan, I. V., \& Hoyer, W. D. (2012). Willingness to pay for cause-related marketing: The impact of donation amount and moderating effects. Journal of Marketing Research, 49(6), 910-927. doi:10.1509/jmr.10.0511

Lee, K. K., \& Zhao, M. (2014). The effect of price on preference consistency over time. Journal of Consumer Research, 41(1), 109-118. doi:10.1086/675219

Lin, Y. C., \& Chang, C. A. (2013). Double standard: the role of environmental consciousness in green product usage. Journal of Marketing, 76(5), 125-134. doi:10.1509/jm.11.0264

Liu, L., Chen, R., \& He, F. (2015). How to promote purchase of carbon offset products: labeling vs. calculation? Journal of Business Research, 68(5), 942-948. doi: 10.1016/j.jbusres.2014.09.021

Luchs, M. G., Naylor, R. W., Irwin, J. R., \& Raghunathan, R. (2010). The sustainability liability: potential negative effects of ethicality on product preference. Journal of Marketing, 74(5), 18-31. doi: $10.1509 /$ jmkg. 74.5 .18

Mazar, N., \& Zhong, C. B. (2010). Do green products make us better people? Psychological Science, 21(4), 494. doi:10.1177/0956797610363538

Montada, L., \& Kals, E. (1995). Perceived justice of ecological policy and proenvironmental commitments. Social Justice Research, 8(4), 305-327.

Newman, G. E., Margarita Gorlin, \& Ravi Dhar. (2014). When going green backfires: how firm intentions shape the evaluation of socially beneficial product enhancements. Journal of Consumer Research, 41(3), 823-839. doi:10.1086/677841

Olsen, M. C., Slotegraaf, R. J., \& Chandukala, S. R. (2014). Green claims and message frames: how green new products change brand attitude. Journal of Marketing, 78(5), 119-137. doi:10.1509/jm.13.0387

P\&G (2016). P\&G 2016 Citizenship Report. Retrieved from http://us.pg.com/2016-CitizenshipReport.html

Preacher, K.J., \& Hayes, A.F. (2008). Asymptotic and Resampling Strategies for Assessing and Comparing Indirect Effects in Multiple Mediator Models. Behavior Research Methods, 40(3), 879-91. doi:10.3758/BRM.40.3.879

Rong, C., Xiaobing, X., \& Hao, S. (2017). Go beyond just paying: effects of payment method on level of construal. Journal of Consumer Psychology, 27(2), 207-217. doi: 10.1016/j.jcps.2016.09.003

Soler, F., Gil, J. M., \& Sanchez, M. (2002). Consumers' acceptability of organic food in Spain: Results from an experimental auction market. British Food Journal, 104(8), 670-687. doi:10.1108/00070700210425921

Sweeney, J. C., \& Soutar, G. N. (2001). Consumer perceived value: the development of a multiple item scale. Journal of Retailing, 77(2), 203-220. doi:10.1016/S0022-4359(01)00041-

Ward, M. K., \& Dahl, D. W. (2014). Should the devil sell Prada? retail rejection increases aspiring consumers' desire for the brand. Journal of Consumer Research, 41(3), 590-609. doi:10.1086/676980

Wertenbroch, K., \& Skiera, B. (2013). Measuring consumers' willingness to pay at the point of purchase. Journal of Marketing Research, 39(38), 228-241. doi:10.1509/jmkr.39.2.228.19086

Wolinsky, A. (1983). Prices as signals of product quality. Review of Economic Studies, 50(4), 647-658. doi: $10.2307 / 2297767$

Xia, L., Monroe, K. B., \& Cox, J. L. (2004). The price is unfair! A conceptual framework of price fairness perceptions. Journal of marketing, 68(4), 1-15. doi:10.1509/jmkg.68.4.1.42733

Zeithaml, V. A. (1988). Consumer perceptions of price, quality, and value: a means-end model and synthesis of evidence. Journal of Marketing, 52(3), 2-22. doi:10.2307/1251446 


\section{APPENDIX A}

\section{Green-signal}

Compared with traditional products, environmentally-friendly products have common and specific attributes.

Traditional products mainly focus on the cost and relationship between supply and demand of products. As a high-tech product, it is very important to pay more attention on the costs for a company with green products. Environmentally friendly products are high value-added products before they are put into industrial production. There must be a large amount of investment in research, and the technology development is often accompanied by great risks. Once the development fails, it means that the huge cost in the research and development phase will not be recovered. At the same time, environmentally friendly products are still in their infancy in China, most of them are new products, involving new process technologies. Production companies also need to invest huge amounts of money in equipment replacement, process adjustment, and plant renovation. Therefore, the cost of green products in R \& D and production is large. If the technology involved in its production is the technology transfer of the scientific research unit, it must pay a technology transfer fee. If advanced technology is introduced, the cost of introducing technology must be paid. It has been expounded the input cost of green products is much higher than that of traditional products. Accordingly, it is natural that the price of green products is higher than that of similar common products. Only in this way, enterprises have profit margins can maintain production for a long time.

\section{Quality-signal}

In a fully competitive market, the attributes of workmanship, quality, durability, and quality of the goods are related to the price, which means you get better products when you pay more, low-priced products generally own lower costs and quality. The saying products with inferior quality are sold at a low price can better reflect the market law.

High-quality products, owing to strict management systems and requirements for raw materials and manufacturing processes, rejecting to cheat in production and reduce materials, so it will inevitably take a certain cost, and the price will not be too low. No matter how the merchants use various means to improve the process, the cost will not change too much, and the quality problem is often hidden behind the unusual low price.

High quality products are mainly reflected on the value. For example, the Marmot bicycles always select good materials and comply with good rules in the production. After a series of meticulous processes, Marmot produces high-quality bicycles, which spreads from mouth to mouth, and everyone wants to buy it.

In general, determining the quality of good goods is a system engineering problem. The factors that constitute a good quality are not often single, but determined by the degree of excellence of the various parts of the system. Therefore, the goodness of a good product mainly reflects the excellence of its details, is the absolute excellence of the overall quality. Behind these good qualities, it is the accumulation and precipitation of the design team for more than ten years or even decades, as well as the intention and strict quality control during manufacturing.

\section{Description of Green Products}

Light source is the leading brand of table lamp company. Light Source's LED smart desk lamp ranks 1 st in sales. It is characterized by the following features: first, the lamp has no visual strobe. Strobe is like impurities in light, the less strobe, the more comfortably the eyes feel. Light Source uses advanced technology to stabilize the light source, uniform the light, and reduce the invisible stroboscopic to the lowest level in the industry; second, no step in the adjustment of brightness color and temperature., users can make the light change smoothly, like water flowing naturally through the unique advanced technology of Light Source; third, professional scene optimization. After a large amount of data analysis, Light Source company design four scenarios, according to professional color temperature and brightness 
design, four LED intelligent modes meet the various needs; fourth, it is designed simply and used for a long time: elegant and beautiful design, better heat dissipation can not only give full play in the performance of the bulb, keep the light soft and uniform, but also extend the service life.

Recently, in response to the state's call for environment protection in the lighting industry, Light source has introduced a new type of LED smart desk lamp, which has made great environmental improvements on the basis of the original product. Tests by international authoritative third-party organizations show that the new type of LED smart desk lamp has better environmental protection effects than any other brand of smart desk lamp on the market.

\section{Premium}

As a result, the price of the new intelligent desk lamp is $10 \%$ higher than that of the original desk lamp owing to the huge investment in environmental research and development of the new desk lamp.

\section{Original Price}

The price of the new intelligent lamp keeps the same with the original lamp. 


\section{APPENDIX B}

\begin{tabular}{l|l}
\hline \multicolumn{1}{c|}{ Self-concern } & \multicolumn{1}{c}{ Other-concern } \\
\hline I & We \\
\hline By myself & Love \\
\hline Income & Help \\
\hline Personal & Public \\
\hline Cost-effective & Honor \\
\hline Profit & Worthy \\
\hline Self & Glory \\
\hline Direct & Indirect \\
\hline Functional & Others \\
\hline Interest & Contribution \\
\hline
\end{tabular}

Smurfs is the leading brand in the liquid detergent market. The liquid detergent with all round effect of Smurfs sales well, it owns the following characteristics: first, efficient: a breakthrough efficient cleansing factor, easy to collapse a variety of stubborn stains, it makes the clothing washed like a new one; second, high concentration: liquid formula, just a little bit, you can clean the whole tube of clothing; third, easy to rinse. It just need to rinse 1-2 times owing to a unique foam control technology; fourth, cleansing: rapid dissolution of water and the release of active factor guarantees the cleansing effect; fifth, protect your hands: a mild neutral formula, you will not feel burning sensation when hand washing; sixth: color protection: it protects the clothing colors and fibers, so that clothing lasts bright as new, soft and smooth.

\section{Government Subsidies Condition}

Recently, Smurfs launched the new liquid detergent in response to the call of the country's environmental protection in the cleaning industry, this new liquid detergent owns improvement significantly on the basis of the original product, the international authoritative of the third-party testing showed this new liquid detergent shows better environmental protection effects significantly compared to the original product. Due to Smurfs investing huge costs in this new liquid detergent about environment enhancements. As a result of environmental protection, the government offers this new product a certain degree of government subsidies, however, due to Smurfs in the new liquid detergent research and development costs are huge, the price of the new liquid detergent than the original liquid detergent rose $5 \%$.

\section{Control Condition}

Recently, Smurfs launched the new liquid detergent in response to the call of the country's environmental protection in cleaning industry, the international trusted third authority showed that this new liquid detergent shows better environmental protection effects significantly compared to the original products. Due to Smurfs investing huge costs in this new liquid detergent about environment enhancements, the price of the new liquid laundry detergent liquid than the original rose by $5 \%$. 